\title{
A novel mechanical simulator for hands-on bariatric endoscopy training in intragastric balloon placement
}
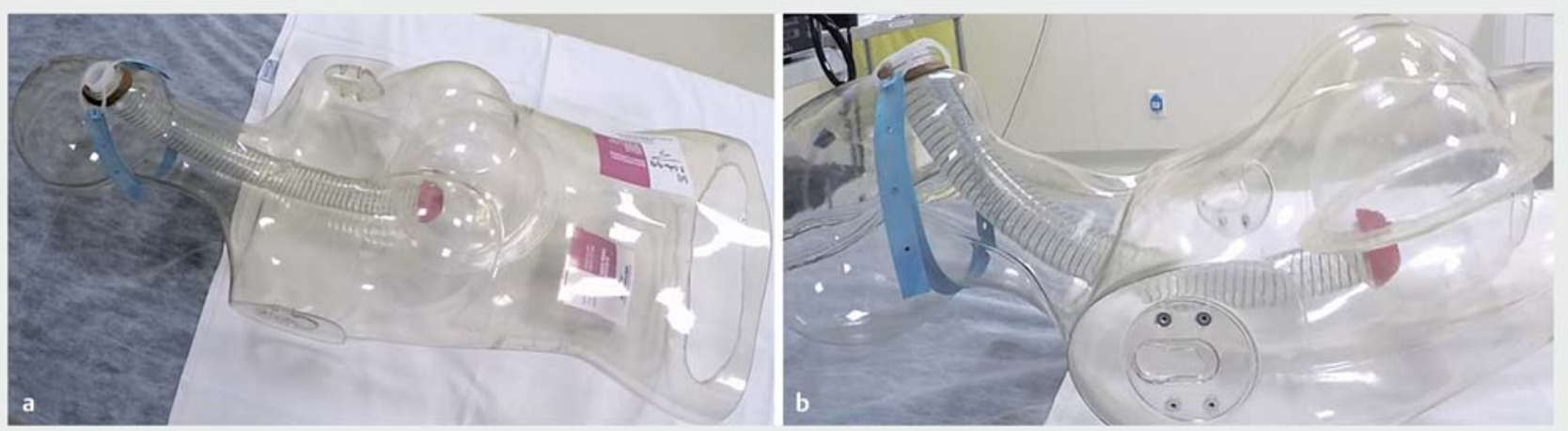

Fig. 1 The LELLA model (EndoWorks LLC, Florida, USA) is shown in: a frontal view; b lateral view focusing on the main components of the upper gastrointestinal tract.

Bariatric endoscopy is a novel and expanding field in gastrointestinal (GI) endoscopy [1]. The most common bariatric endoscopy procedure is intragastric balIoon (IGB) placement [2]. Currently most training occurs with a proctor and a patient. Of course, this approach has potential ethical disadvantages [3], and obtaining the skills for IGB placement using an ex vivo hands-on model would be an ideal solution [4].

We developed a novel mechanical simulator for endoscopic hands-on training with the IGB procedure (LELLA model; EndoWorks LLC, Florida, USA). The model consists of a transparent polycarbonate resin phantom with a fully accessible upper GI tract ( $\triangleright$ Fig. 1; Video 1 ). The IGB placement is carried out step by step with endoscopic, as well as external, visual control, which allows an extended comprehensive view of the physics applied in IGB placement and retrieval ( $\triangleright$ Video 1 ). The esophagus was developed from a plastic conduit of $3 \mathrm{~cm}$ in diameter. It connects proximally to a standard mouthpiece and distally to a red rubber ring, which simulates the gastroesophageal junction and cardia region, an important anatomical landmark for the IGB procedure. The stomach model is a round acrylic based chamber of $20 \mathrm{~cm}$ in diameter and supports all Food and Drug Adminis-

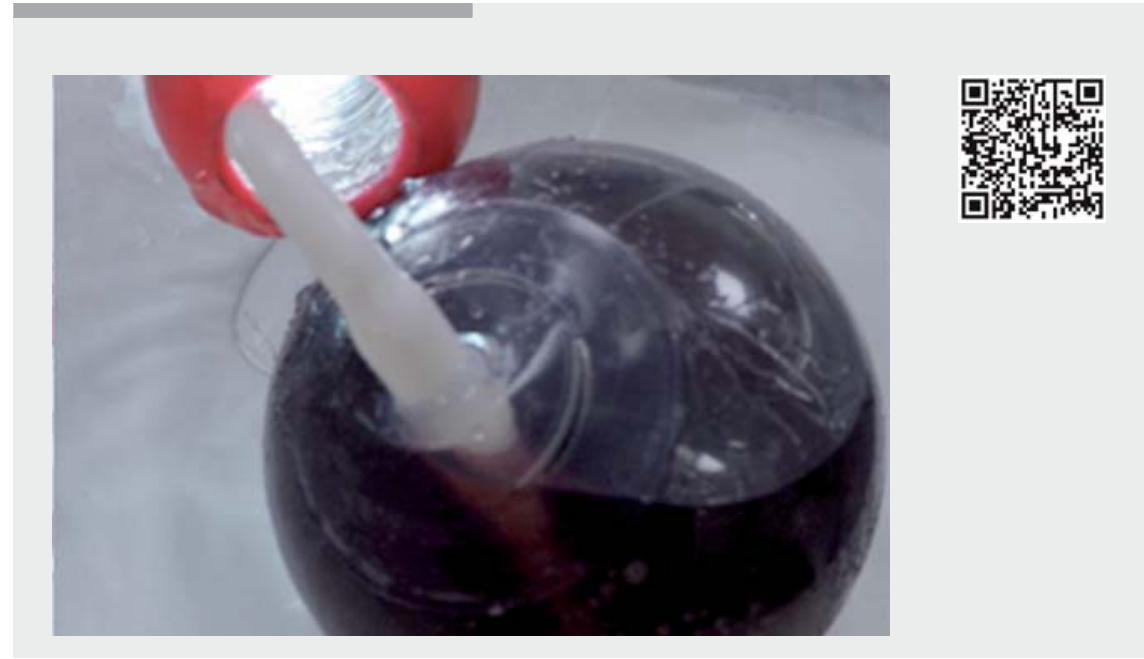

Video 1 The video shows a training session using the Spatz 3 Adjustable Balloon System (Spatz FGIA, Inc., New York, USA), which is placed and withdrawn using the LELLA model simulator (EndoWorks LLC, Florida, USA).

tration (FDA)-approved single IGBs. For the purpose of this video, we used the Spatz 3 Adjustable Balloon System (Spatz FGIA, Inc., New York, USA) (\ Fig. 2).

The IGB was filled with $600 \mathrm{~mL}$ of purple isotonic drink (Gatorade) allowing several reuses of the device and thereby reducing the costs associated with training ( $\triangleright$ Fig. 2). IGB systems that require drilling are an exception as they are ruptured after one use. In addition, the use of isotonic drinks avoids staining the pro- totype, which can be an issue when using a saline and methylene blue solution. Balloon emptying is carried out after retrieving the retractile drainage catheter with a rat-tooth forceps and aspirating the fluid using a negative pressure aspiration system ( $>$ Fig. 2; $>$ Video 1 ). After endoscopically confirming complete shrinkage of the IGB, the decompressed balloon is withdrawn through the esophagus and mouthpiece. 

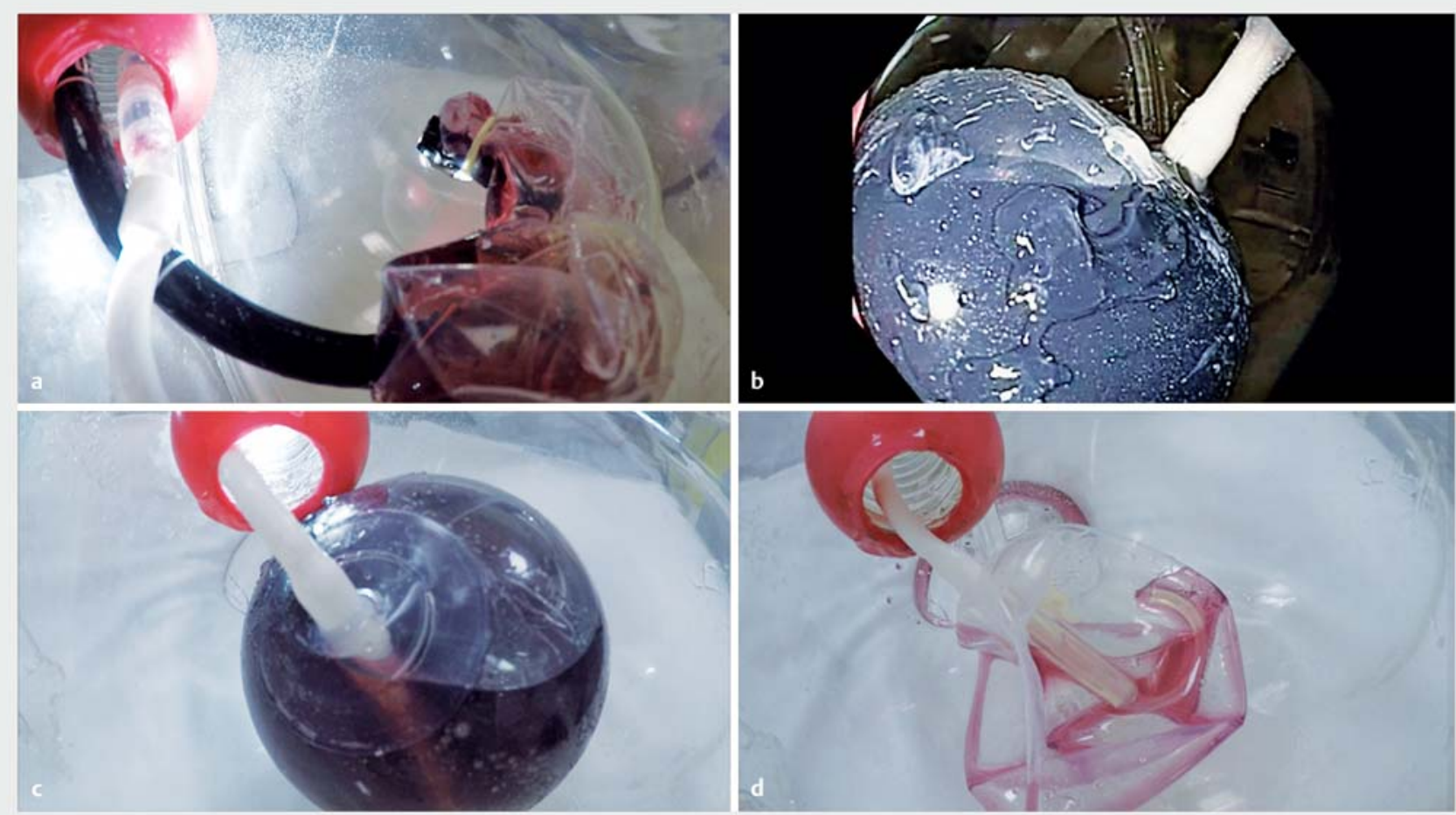

- Fig. 2 Placement of an intragastric balloon using the simulator. a External view at the start of the balloon filling, which is done with the scope fully retroflexed to view the cardia, showing the retractile drainage catheter connection. $\mathbf{b}$ Endoscopic view showing the final appearance of the balloon at full capacity. $\mathbf{c}$ External view of fully filled intragastric balloon. $\mathbf{d}$ The intragastric balloon after emptying.

To the best of our knowledge, this is the first description of a mechanical simulator for bariatric endoscopy training that focuses on the IGB procedure. Because this model is made of widely available materials, it is a convenient and inexpensive alternative to live animal models and requires no specific infrastructure or logistics, with the additional advantage of allowing hands-on training without the need to use "animal use only" scopes. This prototype is now undergoing a validation process to test its impact on improving the IGB procedure performance of trainees.

Endoscopy_UCTN_Code_TTT_1AU_2AB

\section{Competing interests}

None

\section{The Authors}

Marco A. D’Assunçao' ${ }^{1}$, Fernando Lander Mota ${ }^{1}$, Lucas S. Nova da Costa ${ }^{1}$, Willian Ferreira Igi ${ }^{1}$, Dejan Radenkovic ${ }^{2}$, Alvaro Martinez-Alcalá ${ }^{3}$, Paul T. Kröner ${ }^{4}$

1 Department of Digestive Endoscopy, Hospital Sírio-Libanês, São Paulo, Brazil

2 Clinic for Digestive Surgery, Clinical Center of Serbia, Faculty of Medicine, University of Belgrade, Belgrade, Serbia

3 CIDMA (Centro de Innovaciones Digestivas Martínez Alcalá), Seville, Spain

4 Department of Internal Medicine, Mt. Sinai St. Luke's Roosevelt Hospital Center, New York, USA

\section{Corresponding author}

\section{Marco A. D’Assunçao, MD}

Department of Digestive Endoscopy,

Hospital Sírio-Libanês, Rua Dona Adma Jafet, 91, São Paulo, Brazil

mada.lelo@gmail.com 


\section{References}

[1] Bazerbachi F, Valls EJV, Dayyeh BKA. Recent clinical results of endoscopic bariatric therapies as an obesity intervention. Clin Endosc 2017; 50: 42 - 50

[2] Mathus-Vliegen EMH, Alders PRH, Chuttani $R$ et al. Outcomes of intragastric balloon placements in a private practice setting. Endoscopy 2015; 47: 302-307

[3] Desilets DJ, Banerjee S, Barth BA et al. Endoscopic simulators. Gastrointest Endosc 2011; 73: $861-867$
4] McCashland T, Brand R, Lyden E et al. The time and financial impact of training fellows in endoscopy. CORI Research Project. Clinical Outcomes Research Initiative. Am J Gastroenterol 2000; 95: 3129-3132

\section{Bibliography}

DOI https://doi.org/10.1055/s-0043-114403

Published online: 31.7.2017

Endoscopy 2017; 49: E231-E233

(c) Georg Thieme Verlag KG

Stuttgart · New York

ISSN 0013-726X

\section{ENDOSCOPY E-VIDEOS}

https://eref.thieme.de/e-videos

回回 Endoscopy E-Videos is a free 然故 access online section, reporting 回: on interesting cases and new techniques in gastroenterological endoscopy. All papers include a high quality video and all contributions are freely accessible online.

This section has its own submission website at

https://mc.manuscriptcentral.com/e-videos 